\title{
Complicated Crown-root Fracture Management Using the 180-degree Rotation Method
}

\author{
Saeedeh Mokhtari ${ }^{1}$, Shima Hajian ${ }^{2}$, Iman Sanati ${ }^{3}$
}

\begin{abstract}
Aim: The aim of this article is to report a successful treatment of a complicated crown-root fracture.

Background: The management of complicated crown-root fracture in young patients is challenging as the fracture line is below the bone crest and the pulp is exposed. Treatment options include crown lengthening, orthodontic extrusion, and intentional replantation.

Case description: Here, a case of complicated crown-root fracture of tooth number 11 in a ten-year-old boy is presented. Intentional replantation with $180^{\circ}$ rotation and slight extrusion and fixation was performed. In addition, root canal therapy was done and tooth was restored with a composite resin after four weeks. The patient was asymptomatic clinically and radiographically after three-year follow-up.

Conclusion: Intentional replantation with $180^{\circ}$ rotation is a valuable treatment for crown root fractures.

Clinical significance: The management of complicated crown-root fracture using intentional replantation with $180^{\circ}$ rotation can help to maintain natural dentition and interdental papilla.
\end{abstract}

Keywords: Case report, Tooth crown/injuries, Tooth fractures/surgery, Tooth replantation.

International Journal of Clinical Pediatric Dentistry (2019): 10.5005/jp-journals-10005-1625

\section{BACKGROUND}

Maxillary central incisors are the most commonly involved teeth during dental trauma. ${ }^{1}$ Crown-root fracture originates in the crown and extends to the root involving enamel, dentin, and cementum. It comprises $5 \%$ of dental injuries, which occur mostly due to direct trauma from horizontal or frontal impacts. ${ }^{2}$ The involvement of the pulp could compromise the fracture and sometimes in these injuries, fracture line extends longitudinally toward sub-gingival area interfering the biologic width. ${ }^{3}$ Biologic width is defined as a distance between the gingival margin to bone crest including gingival sulcus, junctional epithelium, and conjunctive attachment and its average is $2 \mathrm{~mm}$. It serves as a barrier against bacteria and their products infiltration ${ }^{4}$ and should not be impinged while restoring the tooth crown in order to preserve the periodontal tissue.

Poor prognosis of teeth with subcrestal crown-root fracture generally results in the extraction of the tooth. ${ }^{5}$ However, in order to manage subgingival caries and fracture, which interfere biologic width several treatment modalities such as apically positioned flap, orthodontic extrusion, and crown lengthening (osteotomy) could be performed. ${ }^{6}$ The most important shortcomings of surgical managements in the esthetic zone are the possible involvement of adjacent teeth and gingival recession. ${ }^{3}$ Orthodontic extrusion, on the other hand, is a time consuming procedure and might face relapse due to the stretching of periodontal fibers. ${ }^{7}$

Another treatment procedure for the crown-root fracture is intentional replantation also known as intra-alveolar transplantation. In this technique, which was first introduced by Tegsjo et al. ${ }^{8}$ with $86 \%$ success rate after four years, the tooth is extracted and placed and splinted in a more coronal position. A modification of this technique involving $180^{\circ}$ rotation could result in a better restorative outcome and recovering biologic width. ${ }^{3}$ Proper case selection based on clinical and radiographic examinations is the key to success of this procedure. ${ }^{9}$ \begin{tabular}{l}
\hline Department of Pediatric Dentistry, School of Dentistry, Tehran \\
University of Medical Sciences, Tehran, Iran \\
${ }^{2}$ Dental School, Ghent University, Ghent, Belgium \\
${ }^{3}$ Department of Pedodontics, Private Practice, Tehran, Iran
\end{tabular}

Corresponding Author: Shima Hajian, Dental School, Ghent University, Ghent, Belgium, Phone: +32 471052751, e-mail: shima.hajian@ymail.com How to cite this article: Mokhtari S, Hajian S, et al. Complicated Crownroot Fracture Management Using the 180-degree Rotation Method. Int J Clin Pediatr Dent 2019;12(3):247-250.

Source of support: Nil

Conflict of interest: None

This article presents a successful treatment of a complicated crown-root fracture of maxillary central incisor by intentional replantation with $180^{\circ}$ rotation in a ten-year-old boy.

\section{Case Description}

A ten-year-old boy was referred to a private dental clinic for the treatment of fracture of tooth number 11 . The patient was generally healthy and had no systemic diseases. Tooth fracture occurred when he fell down the step few days before. No previous treatments were performed on the tooth and the patient had no periodontal disease. Clinical and radiographic examinations showed complicated crownroot fracture of tooth number 11 with pulp exposure (Fig. 1). The coronal segment was the palatal one. The patient had pain on mastication with no other symptoms. Other teeth were normal.

As the fracture line was subcrestal, intentional replantation with $180^{\circ}$ rotation was selected. For this purpose, local anesthesia with 1.8 $\mathrm{mL}$ of $2 \%$ of lidocaine and epinephrine $(1: 100,000)$ was administered. The coronal segment was removed and the apical segment, then, was extracted from its socket very carefully using flat-beak forceps only. Root segment was evaluated for other possible fractures and then replanted in the socket in an extruded and $180^{\circ}$ rotated position (Fig. 2). Since

(c) The Author(s). 2019 Open Access This article is distributed under the terms of the Creative Commons Attribution 4.0 International License (https://creativecommons. org/licenses/by-nc/4.0/), which permits unrestricted use, distribution, and non-commercial reproduction in any medium, provided you give appropriate credit to the original author(s) and the source, provide a link to the Creative Commons license, and indicate if changes were made. The Creative Commons Public Domain Dedication waiver (http://creativecommons.org/publicdomain/zero/1.0/) applies to the data made available in this article, unless otherwise stated. 


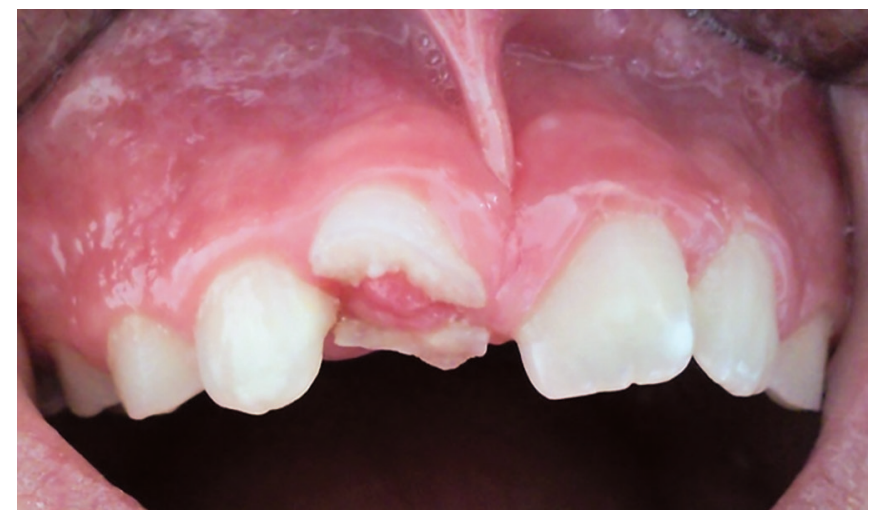

Fig. 1: Crown-root fracture of tooth number 11. Fracture line extends from the labial to the subgingival palatal side

the tooth had some mobility, fixation was done by suture splinting (Fig. 3). Amoxicillin ( $250 \mathrm{mg}$ ) and chlorhexidine $0.12 \%$ mouthwash was prescribed for seven days. After two weeks, the sutures were removed and pulp treatment was initiated. For reducing periodontal inflammation, calcium hydroxide was applied into the canal (Fig. 4). At the fourth-week follow-up, the patient had no symptoms. Clinical and radiographic examinations also revealed no pathologic signs; so the root canal therapy was completed with gutta-percha and the tooth was restored with light cured composite resin (Fig. 5). At the eighth-week, three month, six month, one year, and two year follow-ups, there were no pathologic signs or symptoms and the radiographic examination also showed normal periapical structures. However, some degree of abnormality was seen in the contour of marginal gingiva (Fig. 6).

\section{Discussion}

Intentional replantation is a technique that could be used for the management of perforations, root resorptions, cervical caries, and crown-root fractures. Although this procedure has been used in relatively large groups of patients with endodontic failures, its application for the management of traumatic injuries is limited to the case reports and series. ${ }^{3,5,9-13}$ Primary studies in this field on dogs showed that careful intentional replantation of tooth can result in permanent success. ${ }^{14}$ The success rate of intentional replantation in clinical studies has been reported between $72 \%$ and $95 \% .^{11,15}$ The management of teeth with upper root fractures and deep cervical caries

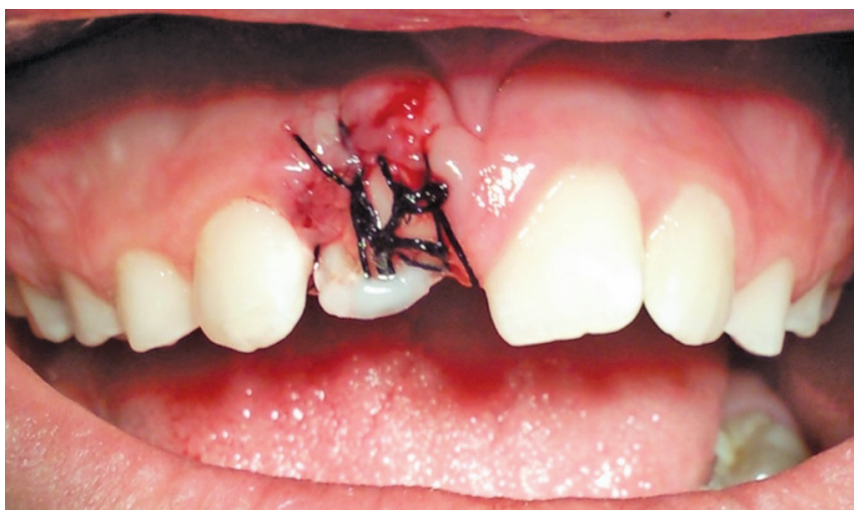

Fig. 3: Suture splint is applied to achieve tooth fixation

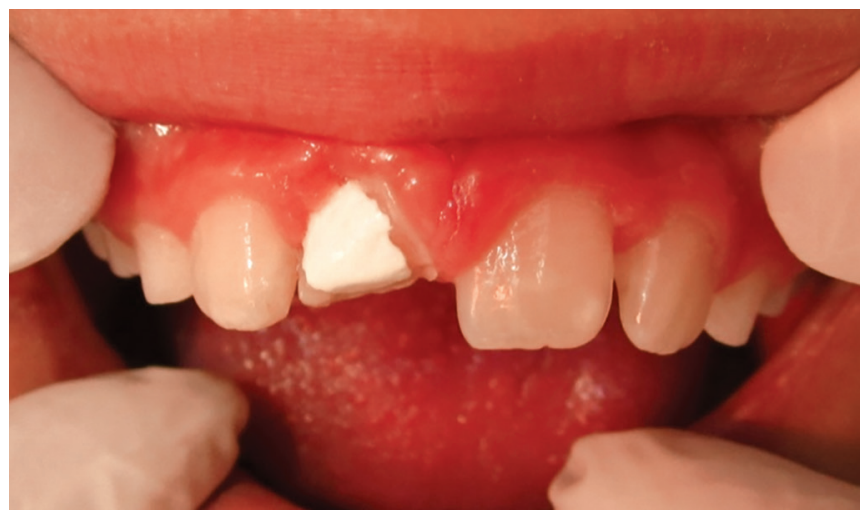

Fig. 4: Splint has been removed and the root canal is filled with calcium hydroxide after 2 weeks

by this technique has been reported to be successful after 10 years. ${ }^{16}$ The case presented herein, intentional replantation with $180^{\circ}$ ration and suture fixation was used. Rotation was done due to deep fracture line and better adaptation of the tooth to its socket. Wang et al. suggested tooth rotation as rotating the tooth will change the palatal subgingival fracture line to the labial supragingival fracture line. ${ }^{17}$ Therefore, the treatment of the labial supragingival fracture line is easier and with better prognosis because of more accessibility and isolation possibility.

Treated tooth prognosis depends on periodontal tissue healing, which is influenced by PDL health. During intentional replantation,
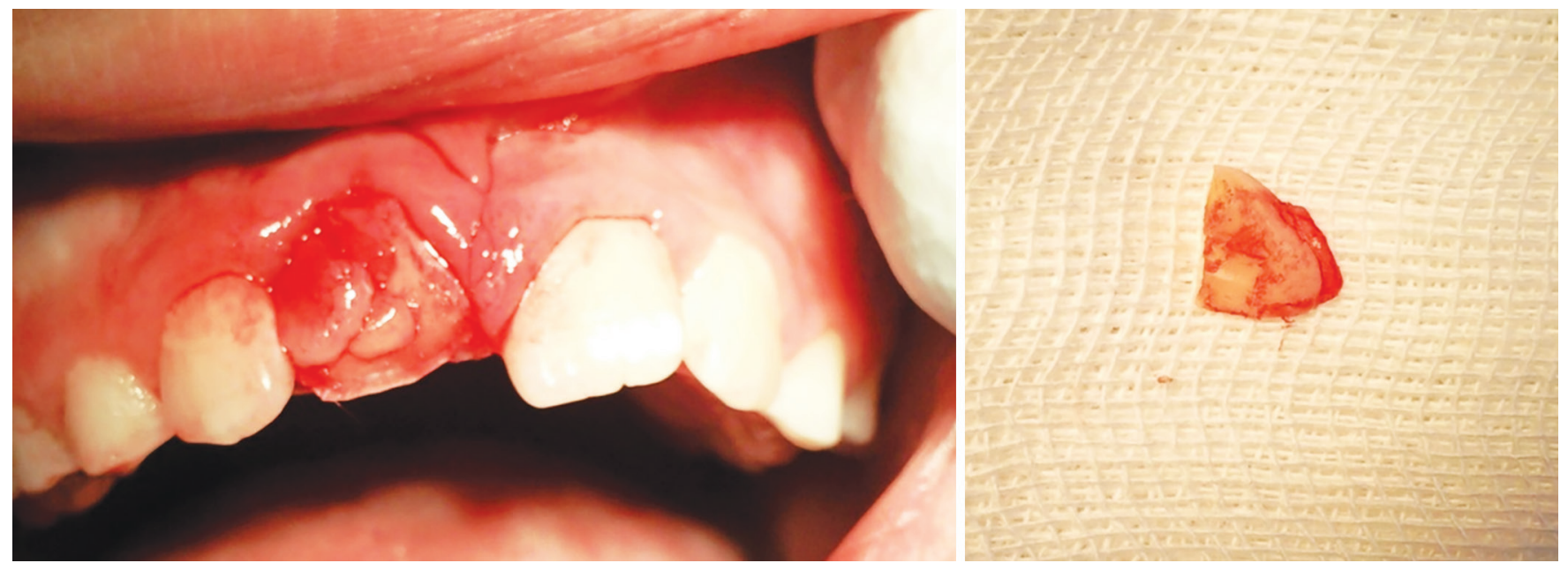

Fig. 2: The coronal segment has been removed and the apical segment is replanted in the $180^{\circ}$ rotation position 


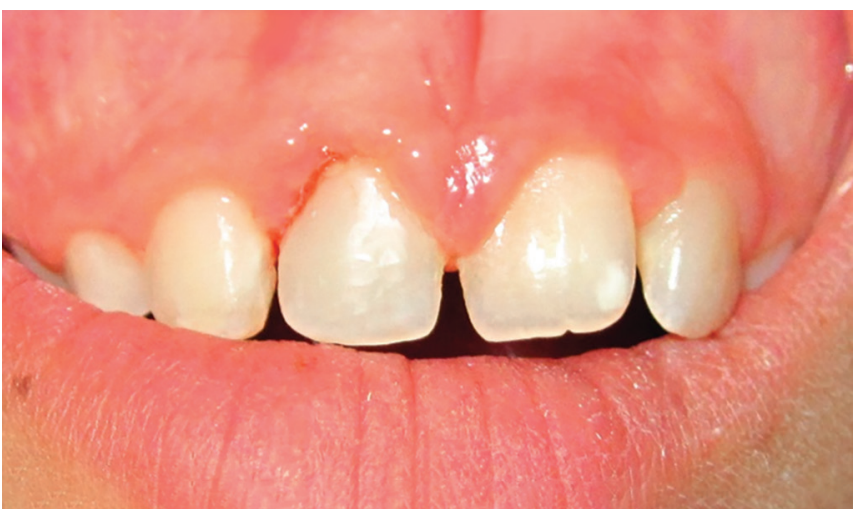

Fig. 5: Root canal is filled with gutta-percha and the tooth is restored with composite resin

atraumatic extraction is an essential factor for successful treatment. Less trauma to the periodontium enable cemental healing and periodontal regeneration and decrease chance of root resorption and ankylosis. While performing intentional replantation, not only a traumatic tooth extraction is critical, but also careful handling of the tooth is necessary for preserving PDL viability. ${ }^{18}$ PDL viability is related to the time out of socket and mechanical trauma while manipulating the tooth for replantation. The destruction of tissues could occur by factors resulting in inflammatory root resorption or replacement resorption. ${ }^{19,20}$ It has been suggested to keep extraoral time less than 15 minutes to minimize PDL damage. ${ }^{5}$ In the presented case, the extraoral time was less than four minutes.

Following replantation, PDL area fills with a coagulum. After 3-4 days, connective tissue formation initiated in PDL and reattachment of epithelium to CEJ occurs during the first week. ${ }^{21}$ Root resorption, if any, could be usually observed on radiographs after 3-4 weeks. ${ }^{3}$ In order to stop root resorption, proper endodontic therapy should be performed. ${ }^{22}$ Some authors ${ }^{23}$ recommended long term application of calcium hydroxide due to its antibacterial properties ${ }^{24}$ or its effect on the retardation of osteoclasts. ${ }^{25}$ In the current case, root canal therapy was initiated with calcium hydroxide and the canal was filled with gutta-percha after 2 weeks. In addition, atraumatic extraction and careful handling decreased the chance of root resorption. Follow-ups have been set at every 6 months to evaluate treatment success based on clinical and radiographic examinations. During 3 years of follow-up, no sign of root resorption on periapical radiographs was present. However, the marginal gingiva of the labial side shows some degree of hyperplasia and therefore, it is not normal in contour. Since there is no periodontal pocket, the periodontal tissue may be considered healthy and the hyperplastic tissue can be removed to reach complete esthetic.

Some authors have suggested that proper splint duration for the reattachment of PDL fibers is 2 weeks. ${ }^{10,26,27}$ However, it depends on the severity of trauma to PDL and resulted inflammation. Berude et al. demonstrated that following tooth replantation, there are no significant difference in root resorption between rigid splints, nonrigid splints, and no splint. ${ }^{28}$ Here, physiologic splinting of the tooth was performed as the tooth did not adapt in the socket. Within the second week, two-thirds of the periodontal fibers are formed and the tooth could be stabilized in the socket. ${ }^{3}$ Therefore, the splint was removed after two weeks to avoid root ankylosis or resorption. ${ }^{29}$

The clinicians should also consider alternative therapies such as implant insertion, crown lengthening, and orthodontic extrusion while assessing the cost effectiveness of intentional replantation. Not treating the teeth with the crown root fracture may result in serious pulpal and periodontal involvement. Clinical decision making should be based on patient needs, clinician skills, medical ethics, and evidence-based dentistry. ${ }^{30,31}$ The depth of fracture, length and morphology of root, and location of the tooth influence treatment strategy. ${ }^{17,32}$ If the fracture line is above CEJ, resin restoration is the most conservative treatment. ${ }^{33}$ Implant placement is not recommended during childhood as it acts like ankylosed tooth and results in implant submerging. ${ }^{34}$ Surgical crown lengthening should be performed with caution in anterior maxilla especially in patients with high smile line as it results in undesirable aesthetic outcome. Orthodontic extrusion is the only choice, which preserves pulpal vitality in non-complicated fractures; however, this time consuming procedure leads to the coronal movement of the gingival margin and alveolar bone, which may necessitate some extra procedures. Intentional replantation, on the other hand, result in faster outcomes. Its main advantage is the ability to directly assess fracture line and looking for other possible fractures. ${ }^{32}$ Case selection for performing this procedure should be done with caution. Intentional replantation is contraindicated for teeth with periodontal disease as well as those with divergent or dilacerated roots. ${ }^{35}$

Preserving interdental papilla is also an important consideration in the esthetic zone. In the presented case, composite resin buildup of the tooth crown helped keeping interdental papilla. Functional and aesthetic factors should be assessed prior to intentional replantation. In addition, patient cooperation and his/her attendance in follow-up sessions could limit the application of this treatment. As previously discussed, root resorption could jeopardize tooth prognosis; hence, long term follow-ups are highly recommended.
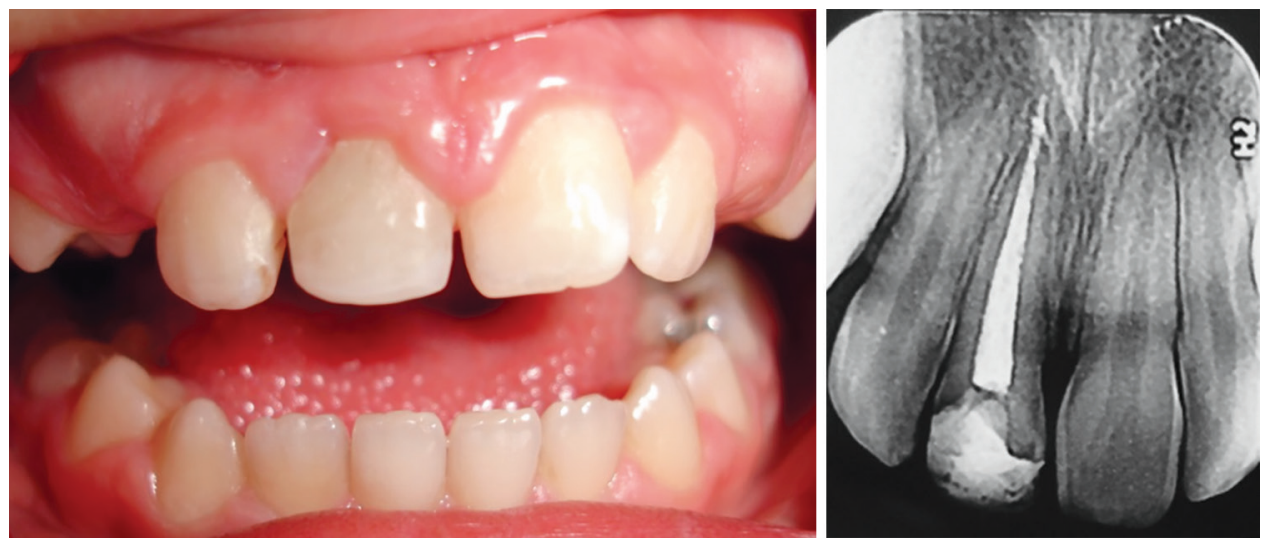

Fig. 6: Clinical and radiographic view of tooth after 3 years 


\section{Conclusion}

Intentional replantation with $180^{\circ}$ rotation is a good optional treatment for the crown root fractures. In this presented case, at the eight-week, three month, six month, one year, and two year follow-ups, there were no pathologic signs or symptoms and the radiographic examination also showed normal periapical structures.

\section{Clinical Significance}

Intentional replantation with $180^{\circ}$ rotation is a valuable treatment for crown root fractures. This technique helps to maintain natural dentition and interdental papilla. Root resorption is a possible complication, which could be avoided by preserving PDL health. Hence, this procedure should be performed with the least trauma to PDL and long term follow-ups are indicated.

\section{Acknowledgement}

We have not included acknowledgments in our manuscript due to the fact that we have not received substantial contributions from non-authors.

\section{References}

1. Shulman JD, Peterson J. The association between incisor trauma and occlusal characteristics in individuals 8-50 years of age. Dent Traumatol 2004;20(2):67-74. DOI: 10.1111/j.1600-4469.2004.00234.x.

2. Andreasen JO, Andreasen FM. Crown-root fractures. In: Andreasen JO, Andrasen FM, Andersson L. ed. Textbook and Color Atlas of Traumatic Injuries to the Teeth, 4th ed. Oxford: Blackwell; 2007. pp. 314-366.

3. Bittencourt GS, Almeida F, et al. Intentional replantation with tooth rotation as indication for treatment of crown-root fractures. Braz J Dent Traumatol 2009;1(1):2-6.

4. Padbury Jr A, Eber R, et al. Interactions between the gingiva and the margin of restorations. J Clin Periodontol 2003;30(5):379-385. DOI: 10.1034/j.1600-051X.2003.01277.x.

5. Chung MP, Wang SS, et al. Management of crown-root fracture tooth by intra-alveolar transplantation with 180 -degree rotation and suture fixation. Oral Surg Oral Med Oral Pathol Oral Radiol Endod 2010;109(2):e126-e130. DOI: 10.1016/j.tripleo.2009.09.014.

6. Hempton TJ, Dominici JT. Contemporary crown-lengthening therapy: a review. J Am Dent Assoc 2010;141(6):647-655. DOI: 10.14219/jada. archive.2010.0252.

7. Yuzugullu B, Polat $O$, et al. Multidisciplinary approach to traumatized teeth: a case report. Dent Traumatol 2008;24(5):e27-e30. DOI: 10.1111/j.1600-9657.2008.00603.x.

8. Tegsjo $\mathrm{U}$, Valerius-Olsson $\mathrm{H}$, et al. Intra-alveolar transplantation of teeth with cervical root fractures. Swed Dent J 1978;2(3):73-82.

9. Fariniuk LF, Ferreira EL, et al. Intentional replantation with 180 degrees rotation of a crown-root fracture: a case report. Dent Traumatol 2003;19(6):321-325. DOI: 10.1046/j.1600-9657.2003.00216.x.

10. Bindo TZ, de Morais EC, et al. Multidisciplinary approach of a crownroot fracture using intentional replantation: a case report. Pediatr Dent 2010;32(5):428-432.

11. Sahebi S, Dolatkhah V, et al. Management of a crown-root fracture in central incisors with 180 rotation: a case report. Iran Endod J 2011;6(4):183-187.

12. Kim DS, Shin DR, et al. Management of complicated crown-root fractures using intentional replantation: two case reports. Dent Traumatol 2013;29(4):334-337. DOI: 10.1111/j.1600-9657.2011.01075.x.

13. Shanmugam J, Mahendran K, et al. Management of complicated Crown root fractured teeth by intra alveolar transplantation with 180 rotation: case series. SRM J Res Dent Sci 2014;5(3):203. DOI: 10.4103/0976-433X.138763.

14. Sherman Jr P. Intentional replantation of teeth in dogs and monkeys. JDent Res 1968;47(6):1066-1071.DOI:10.1177/00220345680470061101.
15. Peer M. Intentional replantation - a 'last resort' treatment or a conventional treatment procedure? nine case reports. Dent Traumatol 2004;20(1):48-55. DOI: 10.1046/j.1600-4469.2003.00218.x.

16. Kahnberg KE. Intra-alveolar transplantation. I. A 10-year follow-up of a method for surgical extrusion of root fractured teeth. Swed Dent J 1996;20(5):165-172.

17. Wang Z, Heffernan $M$, et al. Management of a complicated crownroot fracture in a young permanent incisor using intentional replantation. Dent Traumatol 2008;24(1):100-103. DOI: 10.1111/j.16009657.2006.00487.x.

18. Asgary S, Alim Marvasti $L$, et al. Indications and case series of intentional replantation of teeth. Iran Endod J 2014;9(1):71-78.

19. Polimeni G, Xiropaidis AV, et al. Biology and principles of periodontal wound healing/regeneration. Periodontol 2006;41:30-47. DOI: 10.1111/j.1600-0757.2006.00157.x.

20. Pohl Y, Filippi A, et al. Results after replantation of avulsed permanent teeth. II. Periodontal healing and the role of physiologic storage and antiresorptive-regenerative therapy. Dent Traumatol 2005;21(2): 93-101. DOI: 10.1111/j.1600-9657.2004.00298.x.

21. Andreasen JO. A time-related study of periodontal healing and root resorption activity after replantation of mature permanent incisors in monkeys. Swed Dent J 1980;4(3):101-110.

22. Pohl Y, Filippi A, et al. Results after replantation of avulsed permanent teeth. I. Endodontic considerations. Dent Traumatol 2005;21(2):80-92. DOI: 10.1111/j.1600-9657.2004.00297.x.

23. Caliskan MK, Turkun M, et al. Delayed replantation of avulsed mature teeth with calcium hydroxide treatment. J Endod 2000;26(8):472-476. DOI: 10.1097/00004770-200008000-00011.

24. Sathorn C, Parashos P, et al. Antibacterial efficacy of calcium hydroxide intracanal dressing: a systematic review and meta-analysis. Int Endod J 2007;40(1):2-10. DOI: 10.1111/j.1365-2591.2006.01197.x.

25. Mohammadi Z, Dummer PM. Properties and applications of calcium hydroxide in endodontics and dental traumatology. Int Endod J 2011;44(8):697-730. DOI: 10.1111/j.1365-2591.2011.01886.x.

26. Flores MT, Andersson L, et al. Guidelines for the management of traumatic dental injuries. II. Avulsion of permanent teeth. Dent Traumatol 2007;23(3):130-136. DOI: 10.1111/j.1600-9657.2007.00605.x.

27. Flores MT, Andersson L, et al. Guidelines for the management of traumatic dental injuries. I. Fractures and luxations of permanent teeth. Dent Traumatol 2007;23(2):66-71. DOI: 10.1111/j.16009657.2007.00592.x.

28. Berude JA, Hicks ML, et al. Resorption after physiological and rigid splinting of replanted permanent incisors in monkeys. J Endod 1988;14(12):592-600. DOI: 10.1016/S0099-2399(88)80056-6.

29. Andersson L, Andreasen JO, et al. International Association of Dental Traumatology guidelines for the management of traumatic dental injuries: 2. Avulsion of permanent teeth. Dent Traumatol 2012;28(2):88-96. DOI: 10.1111/j.1600-9657.2012.01125.x.

30. Iqbal MK, Kim S. A review of factors influencing treatment planning decisions of single-tooth implants vs preserving natural teeth with nonsurgical endodontic therapy. J Endod 2008;34(5):519-529. DOI: 10.1016/j.joen.2008.01.002.

31. Gotfredsen K, Carlsson GE, et al. Implants and/or teeth: consensus statements and recommendations. J Oral Rehabil 2008;35(Suppl 1):2-8. DOI: 10.1111/j.1365-2842.2007.01833.x.

32. Olsburgh S, Jacoby $\mathrm{T}$, et al. Crown fractures in the permanent dentition: pulpal and restorative considerations. Dent Traumatol 2002;18(3):103-215. DOI: 10.1034/j.1600-9657.2002.00004.x.

33. Naudi $A B$, Fung $D E$. Tooth fragment reattachment in multiple complicated permanent incisor crown-root fractures - a report of two cases. Dent Traumatol 2008;24(2):248-252. DOI: 10.1111/j.16009657.2007.00526.x.

34. Davarpanah M, Martinez H, et al. Clinical Manual of Implant Dentistry: Contraindication for Dental Implants. St. Louis: Quintessence Publishing Co Ltd, 2003; pp. 1-20.

35. Wolcott J, Rossman LE. Intentional replantation of endodontically treated teeth: an update. Compend Contin Educ Dent 2003;24(1): $68-72,74$. 